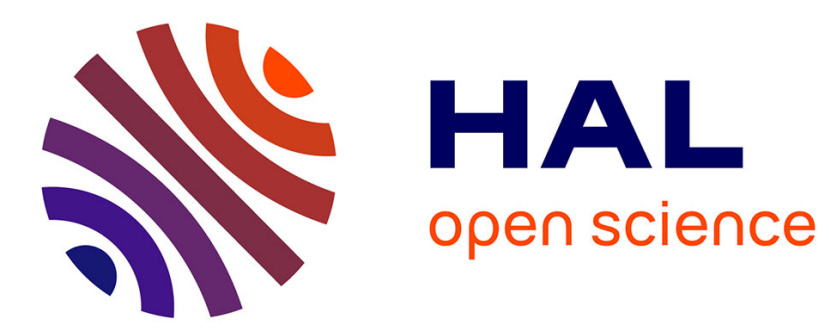

\title{
Absorption of atomic and molecular species in carbon cellular structures (Review Article)
}

\author{
N V Krainyukova, B. Kuchta, L. Firlej, P Pfeifer
}

\section{To cite this version:}

N V Krainyukova, B. Kuchta, L. Firlej, P Pfeifer. Absorption of atomic and molecular species in carbon cellular structures (Review Article). Low Temperature Physics, 2020, 46 (3), pp.271-285. 10.1063/10.0000705 . hal-02512005

\section{HAL Id: hal-02512005 \\ https://hal.science/hal-02512005}

Submitted on 19 Mar 2020

HAL is a multi-disciplinary open access archive for the deposit and dissemination of scientific research documents, whether they are published or not. The documents may come from teaching and research institutions in France or abroad, or from public or private research centers.
L'archive ouverte pluridisciplinaire HAL, est destinée au dépôt et à la diffusion de documents scientifiques de niveau recherche, publiés ou non, émanant des établissements d'enseignement et de recherche français ou étrangers, des laboratoires publics ou privés. 


\title{
Absorption of atomic and molecular species in carbon cellular structures
}

\section{(Review Article)}

\author{
N.V. Krainyukova ${ }^{1}$, B. Kuchta ${ }^{2,3,4}$, L. Firlej ${ }^{4,5}$, and P. Pfeifer ${ }^{4}$ \\ ${ }^{1}$ B. Verkin Institute for Low Temperature Physics and Engineering of the National Academy of Sciences of Ukraine \\ 47 Nauky Ave., Kharkiv 61103, Ukraine \\ E-mail: krainyukova@ilt.kharkov.ua \\ ${ }^{2}$ Laboratoire Madirel, Aix Marseille University, CNRS, Marseille 13013, France \\ ${ }^{3}$ Department of Chemistry, Wroclaw University of Science and Technology, Wroclaw 50-370, Poland \\ ${ }^{4}$ Department of Physics and Astronomy, University of Missouri, Columbia MO 652011, USA \\ ${ }^{5}$ Laboratoire Charles Coulomb, University of Montpellier, CNRS, Montpellier 34095, France
}

Received October 28, 2019, published online January 27, 2020

\begin{abstract}
The paper presents a brief review of the recent developments in the field of absorption of atomic and molecular species in carbon cellular structures. Such absorbing objects can be distinctly recognized among a large family of carbon porous materials owing to potential and already observed in experiments very high capacity to soak and to keep inside different substances, which at usual conditions outside the porous matrices may often stay only in a gaseous form. High capacity filling is attained owing to single graphene-like walls separating different cells in the whole structures providing their lightweight. This property of cellular structures makes them very promising for numerous technological applications such as hydrogen storage in fuel cells and molecular sieving in membranes made from such structures or for their usage in microelectronics, photovoltaics and production of Li-ion batteries. Independently of the targeted applications gases are good candidates for probing tests of carbon matrices themselves.
\end{abstract}

Keywords: carbon honeycombs, adsorbates in carbon cellular structures, $a b$ initio calculation of adsorbate structures, high-energy electron diffraction.

\section{Contents}

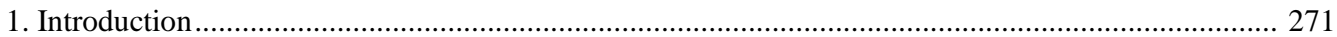

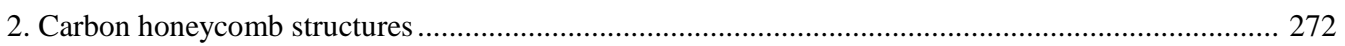

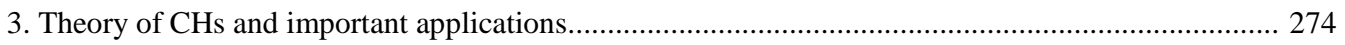

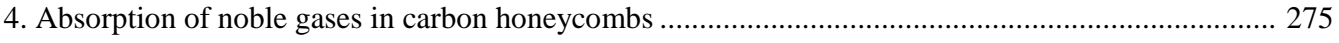

5. Capture of molecular gases in carbon honeycombs........................................................................ 277

6. Activated carbon with local graphene-like pore wall structures as potential enhanced hydrogen

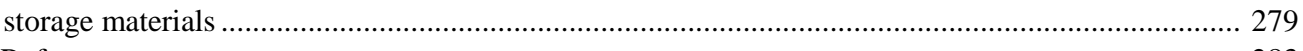

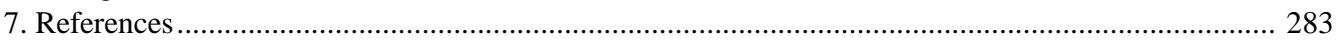

\section{Introduction}

Solid cellular materials can be found everywhere and serve as a basis of all life forms on Earth: wood and other plant parts, living tissues, etc. Therefore their artificial production is crucially important for supporting human society in many targeted (including medical) aspects. Cellular materials have also numerous industrial applications ranging from microelectronics to energy storage, catalysis, and the like.

The progressive growth of Earth population dictates the need to develop clean and renewable energy sources that is closely connected with the other not less important requirement to protect our environment from non-healthy and even dangerous pollutants produced in many industrial branches including energy-related plants. One of the most promising 
fuels for the future is hydrogen most abundant element in the universe. Indeed its combination with oxygen from air produces the electric power in the fuel cells and just warm water. On Earth it can be produced from water involving, for instance, such natural phenomena as tides in the seas. But storage and transportation of hydrogen is a real barrier for its wide usage. Hydrogen is very light and its large amounts can be stored either at very low temperatures or very high pressures. Light porous materials could be good candidates.

Low-dimensional carbon allotropes such as fullerenes, carbon nanotubes, graphene have remarkable properties and have been broadly explored owing to their potential and already found numerous technological applications. Some of these allotropes or their combinations demonstrate growing importance for creating different types of porous or cellular matrices. Filling such structures with different species paves the route to make in this way new materials with unique and demanded properties especially promising in the energy storage and conversion fields.

In quest of carbon structures with the highest porosity there has been invented the experimental method [1], which enabled creating potentially appropriate cellular structures called "carbon honeycombs" (CHs) first identified in the experiment [1] and comprehensively described in the next sections. Such light-weight carbon honeycombs are built of 2D graphene nanosheets and could be promising functional materials for many engineering applications. In particular, CHs structures were proven to allow storing high amounts of different gases surpassing the previous candidate, carbon nanotubes [2,3], by almost twice in storage capacity.

In this review, we show the potential of $\mathrm{CHs}$ for gas storage in CH matrices and outline some other important applications. We further overview several graphene-like pore wall structures with activated carbon as potential enhanced hydrogen storage materials.

\section{Carbon honeycomb structures}

The procedure of production of CHs used in experiments on absorption [1,4-6] most exhaustively described in [1,4] (Fig. 1). Briefly, pure sublimation from graphitic rods thinned in their central parts and heated by the electric current up to graphite sublimation point was used (instead of the most popular method-arc-discharge between two electrodes for carbon film preparation).

In such a method only sublimation of graphitic patches was allowed. In such patches tight $s p^{2}$ network is preserved while weaker van der Waals bonding between graphitic layers is destroyed. Carbon patches fly and land on a nearby surface to form nanostructures. They may form "upright standing graphene formation(s) on substrates" [7] and can merge with previously deposited patches at big enough angles forming junction structures [8]. This occurs because the dangling bonds at the edges tend to be closed; therefore junction structures are energetically more favor-

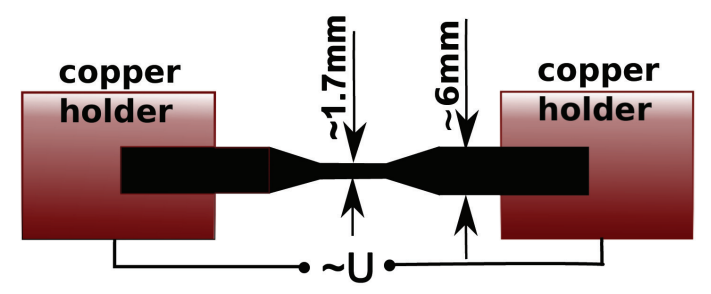

Fig. 1. (Color online) The scheme of the $\mathrm{CH}$ film preparation by means of carbon sublimation from the graphitic rods [4].

able. For these reasons the probability of parallel deposition forming usual graphitic layers is negligible. Such junction structures called in [1] "carbon honeycomb" $(\mathrm{CH})$ are different from other graphitic materials observed previously. In CHs two "wall-chiralities" (armchair and zigzag) may form [9]. Some other modifications similar to CHs [10-13] called "carbon foams" were predicted in theory and in principle are also possible but have not observed yet. Densities of the $\mathrm{CH}$ structures may vary depending on wall widths. Such structures were proved to be good gas absorbers, as it was reported in 2009 [5] before their atomic structure was analyzed [1]. A short popular overview of this newly synthesized carbon form can be found in [14].

High absorption capacity of the structures obtained by the method described above was first observed in 2009 [5] although the structures of carbon matrices were not identified at that moment. High absorption levels $4-6 \%$ in atomic count with respect to carbon atoms in matrices were proved experimentally for heavier inert gases $\mathrm{Kr}, \mathrm{Xe}$ and $\mathrm{CO}_{2}[1,5]$, although experiments with hydrogen have not made yet. Such levels found for the above-mentioned gases are about twice higher as compared with even theoretical predictions for the closest pretender carbon single-wall nanotubes to serve for these purposes. Besides the application of nanotubes is questionable also because in practice it is difficult to open their ends and to provide access to their inner volumes $[2,3]$.

The levels of absorption depend on the channel sizes (see Figs. 2, 3) and therefore can be varied by the preparation conditions. But on the other hand, only physical absorption may not be sufficient to keep light molecules and atoms like $\mathrm{H}_{2}$ or $\mathrm{He}$ at high enough temperatures, especially in wide channels. Therefore it is necessary to find the best compromises between the levels of absorption and upper-temperature limits for keeping hydrogen in such matrices.

In the first experiments $[1,4]$ there were found $\mathrm{CHs}$ only of the zigzag type shown in Fig. 2. But in the more recent study [6] it had been revealed the contribution of the structures not only of the zigzag type (hcZn0) but also armchair (hcA1) with the highest possible density predicted and considered in [9] (Fig. 3). Indeed varying the preparation conditions under sublimation of carbon patches from 

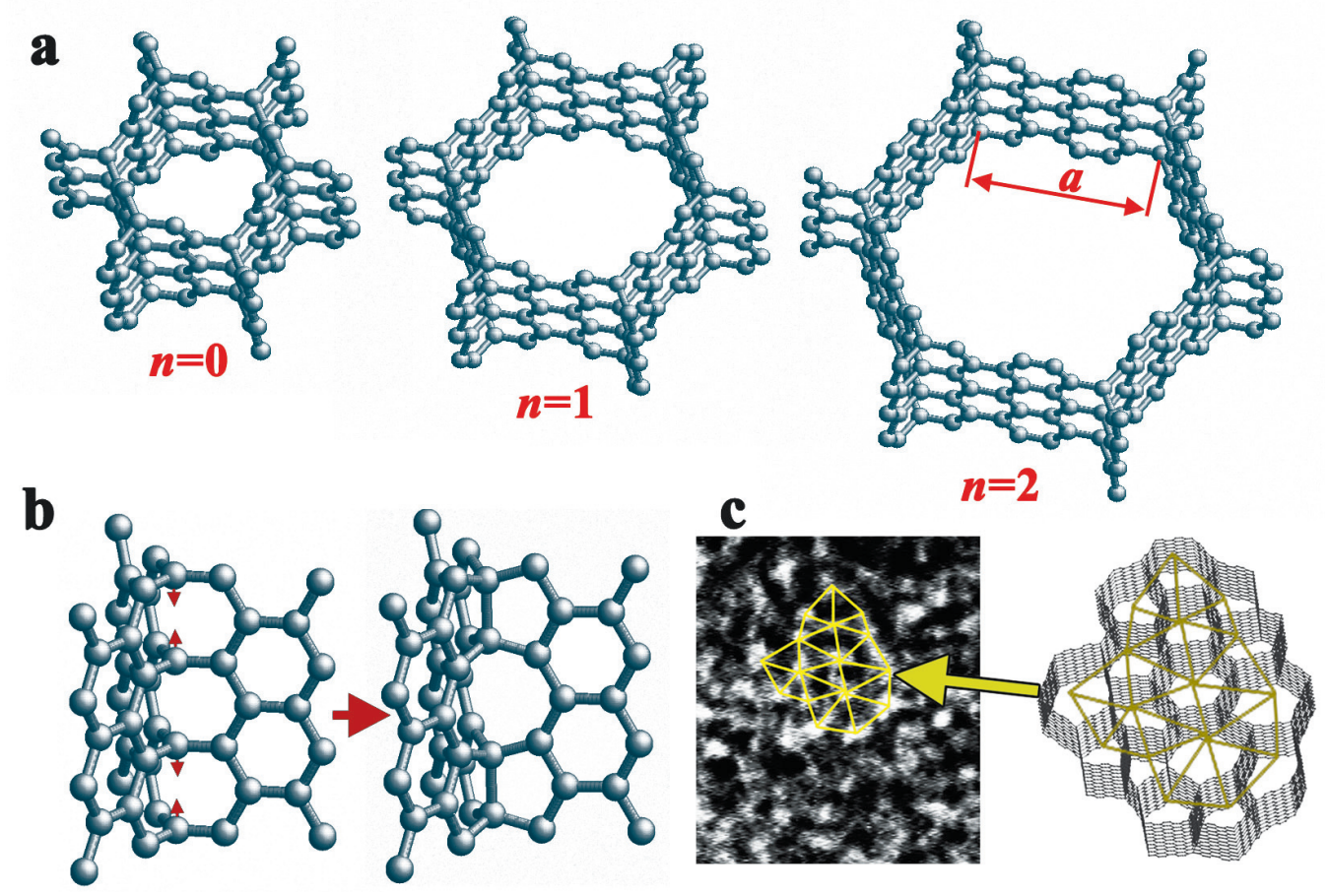

Fig. 2. (Color online) Regular (a) and random (c) CH structures derived from TEM [1]. Here $a=(2.5+1.5 n) r_{N N}$ where $r_{N N}$ is an interatomic distance in graphene ribbons that form walls in CHs and $n$ is an integer. Theoretical relaxation of the regular structures [9] (b).

graphitic rods with the parameters corresponding to the faster deposition it has been found that honeycomb structures are still absolutely dominant. But in these regimes, there was also possible to obtain the armchair type honeycomb structure (hcA1) with thinnest possible for honeycomb channels, which was earlier not identified.

The experimental studies of the $\mathrm{CH}$ structures produced by the method described above as well as composites based on carbon structures filled with absorbed gases were performed in [1,4-6] by means of Transmission High-Energy Electron Diffraction (THEED). The analysis method typically applied to the sets of the diffraction data obtained in

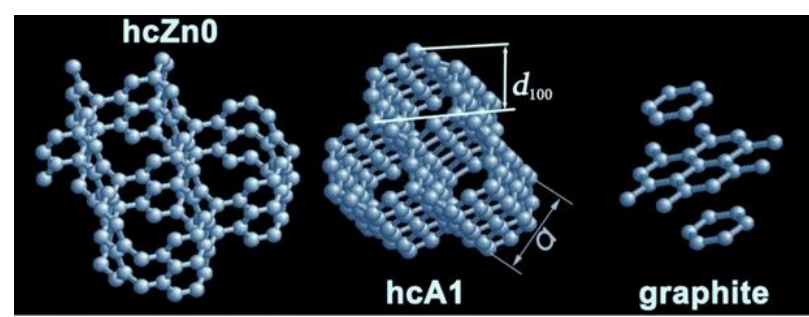

Fig. 3. (Color online) The densest carbon structures derived from the best-fit analysis of experimental diffraction intensities [6]: a fragment of a regular densest honeycomb structure of a zigzag type (hcZn0), the densest honeycomb structure of an armchair type [9] (hcA1) (here $a$ is a parameter of the hexagonal honeycomb lattice) and a small graphitic fragment (Gr), whose contribution to the total diffraction intensity, as a rule, does not exceed $\sim 5 \%$. In the hcA1 structure, the distance $d_{100}$ corresponds to the diffraction peak (100) hcA1 shown in Fig. 4(a). the low-temperature experiment can be briefly described as follows [4,6].

In the expression for the calculated intensities

$I_{\text {calc }}(S)=\exp \left(-\left\langle u^{2}\right\rangle S^{2}\right) f^{2}\left[\frac{1}{(1-t)}+\sum_{k} w_{k} I_{\text {calc }, k}(S)\right]$

$f$ is the atomic scattering factor for electrons and

$$
I_{\text {calc, } k}(S)=\frac{2}{N_{k}}\left[\sum_{m>n} \frac{\sin \left(S r_{m n}\right)}{S r_{m n}}\right]_{k}
$$

is the Debye formula [15] applied for each model structure used in the analysis; here $r_{m n}$ is a distance between a pair of atoms in a structural fragment $k$. We vary such parameters as the mean-square atomic displacements $\left\langle u^{2}\right\rangle$ and probabilities $w_{k}$ of the presence of a structural fragment $k$ comprised of $N_{k}$ atoms in order to find the best fit between the calculated and experimental intensities $I_{\exp }(S)$ (Fig. 4) assuming that $\sum_{k} w_{k}=1$. The value $t$ is introduced for a part of atoms, which belong to different model fragments and give contributions only in the monotonic term $\sim f^{2}$ because oscillating terms with $I_{\text {calc }, k}(S)$ (Eq. (2)) mutually cancel each other in $I_{\text {calc }}(S)$ (Eq. (1)). The electron diffraction intensities $I_{\exp }$ are the functions of the scattering wave vector $S=4 \pi \sin \theta / \lambda$, where $\lambda$ is the de Broglie wavelength of the electrons and $2 \theta$ is the scattering angle.

In the procedure of the comparison of experimental and calculated intensities we apply the reliability factor 

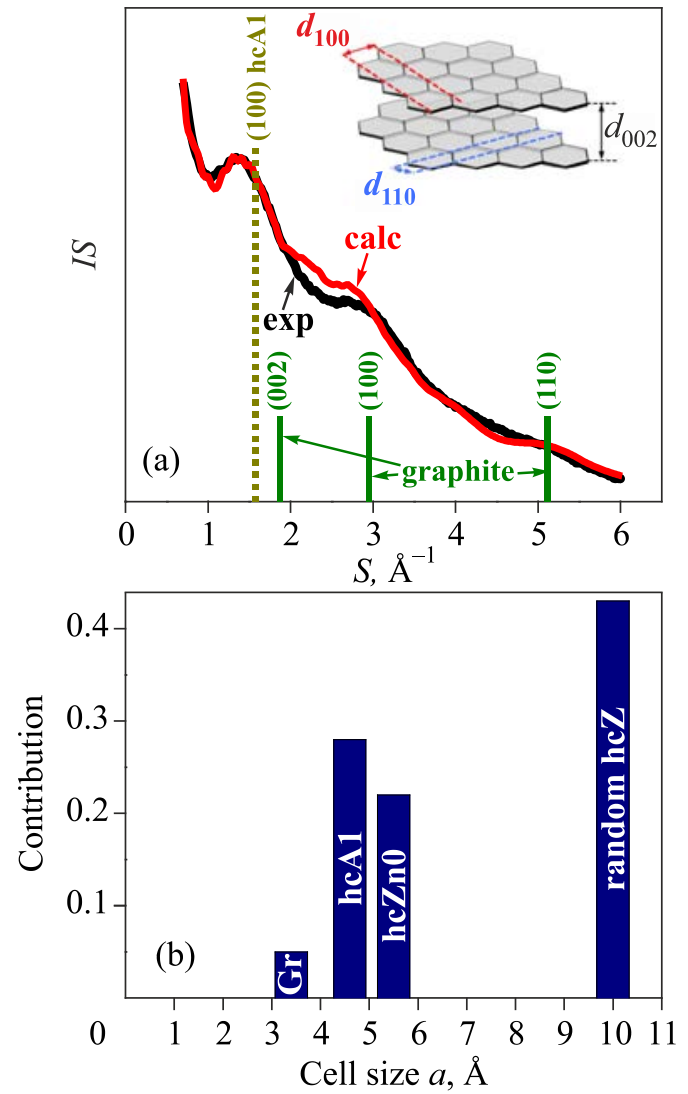

Fig. 4. (Color online) The comparison of experimental (exp) and best-fit calculated (calc) diffraction intensities for the carbon films possessing the cellular structures of a honeycomb type [6]. In the inset, the distances in a graphite fragment corresponding to the positions of different diffraction peaks for graphite are shown. The peak (100) hcA1 corresponds to the distance $d_{100}$ in the hcA1 structure shown in Fig. 3(a). Relative contributions of structural fragments found from the best-fit analysis [6] (b).

$$
R=\frac{\sum_{S}\left|I_{\text {exp }}-I_{\text {calc }}\right|}{\sum_{S}\left(I_{\text {exp }}+I_{\text {calc }}\right)}
$$

with the step $0.02 \AA^{-1}$ in the summation over $S$.

\section{Theory of CHs and important applications}

The absorption properties of carbon cellular structures will be considered in detail in the next sections but here we briefly overview many other potential applications of CHs predicted by theory.

While scaling 2D graphene up to its three-dimensional counterparts there are many significant challenges in maintaining the nature and intrinsic properties of individual graphene sheets in the resulting three-dimensional bulk structures. But the comprehensive theoretical studies of CHs [9,16-23] proved their superb strength and stability. This strength remains at a high level but tunable with different cell sizes $[17,24]$ and crucially depends on defectness of $\mathrm{CH}$ structures [25]. The mechanical simulations [9] showed that the Young's modulus of the structures is de- termined solely by the density of the hinges, and deformations are localized, similar to that of macroscopic honeycombs. Besides, the lattice sizes and its regularity were found to be crucial parameters for the failure strain [9,26,27]. It was demonstrated that under out-of-plane compression, the honeycomb exhibits two critical deformation events, i.e., elastic mechanical instability (including elastic buckling and structural transformation) and inelastic structural collapse [27].

CHs exhibit the negative Poisson's ratio, as large as $\sim 0.32[28,29]$. The Poisson's ratio of carbon honeycomb is anisotropic and sensitive to temperature. Moreover, the carbon honeycomb has phase transformation from normal to auxetic by tensile, along both zigzag and armchair directions. Combined with high strength such a unique and adjustable negative Poisson ratio suggests broad engineering applications of carbon honeycomb.

CHs were also found to be light, thin, yet exceptionally strong energy-absorbing systems [30]. The "giant" energyabsorption capacities of CHs originates from their three-dimensional graphene structures consisting of high-energy $s p^{2}$ and $s p^{3}$ bonds which provide a high plateau stress in a long strain range. When heated above the melting point predicted at $\sim 2200{ }^{\circ} \mathrm{C}$, CHs transit into multi-walled carbon nanotubes [31].

The specific thermal conductivity of $\mathrm{CHs}$ was found to be very high and larger than in most engineering materials $[16,17]$, including metals and high thermal conductivity semiconductors and non-monotonically depends on strains [32]. The thermal conductivity parallel to the honeycomb axis direction is three times or up to one order magnitude higher than that in the perpendicular direction [33-35]. This anisotropy is explained by the direction-dependent effective elastic constants. It was found in the theoretical study [36] that the cell irregularity in random $\mathrm{CH}$ structures found in the experimental studies [1,4] essentially reduces the thermal conductivity of $\mathrm{CHs}$ but it can be improved again by external tensile strain.

The precise calculations of two "wall-chiralities" (armchair and zigzag) performed in [9] showed that reconstruction of the junction lines (hinges) of the zigzag type of CHs resulted in a new structure, which possesses novel unexpected electronic properties. Electronic band structures and conductivity were shown to be determined by the "wall-chiralities" $[9,37,38]$ while electron mobility is very high $[18,39]$. According to [40] the thermoelectric performance of 3D CHs is excellent, an order of magnitude higher than that of graphene. This indicates that this type of $3 \mathrm{D}$ graphene is a powerful candidate for constructing novel thermoelectric materials.

CHs were considered as a new type of topological materials [41], and there were found a phase transition between a specific nexus network and a system with triply degenerate points and additional nodal lines. In the nexus networks, the Landau level spectra show unusual magnetic 
transport properties. It was also revealed [42] that $s p^{2} \mathrm{CHs}$ exhibit antiferromagnetism at the inner edge of the zigzag ribbon component and also at the chain of $s p^{2}$ carbon that joins three zigzag ribbons. At the joint chain, it has spin orientations that alternatively change along the axis and stems from a super-exchange mechanism. The spin-polarization of the zigzag edge owes to the magnetic instability of the localized edge states. Through-hole doping, the zigzag edge antiferromagnetism can be enhanced and stabilized as the magnetic ground state. These results propose CHs as novel magnetic carbon.

Doped CHs are also perspective in the redox catalytic applications of these bulk materials [43,44]. These include oxygen reduction reactions, hydrogen evolution reactions, and $\mathrm{CO}_{2}$ reduction. Besides according to the theoretical prediction [45-47] CHs possess a great potential for $\mathrm{Li}(\mathrm{Na})$-ion batteries production. Indeed such 3D porous carbon materials exhibit the low energy barrier for lithium (or sodium) ion diffusion along the one-dimensional channels, and these $\mathrm{Li}(\mathrm{Na})$-intercalated configurations are all metallic. Therefore CHs can serve as a promising nanoporous scaffold for both lithium and sodium deposition with good electronic conductivity. Lithium/sodium when are inserted into the channels of CHs exists in the form of metal nanorods. In [46,47] it was predicted a high theoretical Li storage capacity (almost twice that of graphite) when the one-dimensional pores are fully filled with lithium/sodium atoms. These results suggest that the CHs could be a very perspective pure carbon anode material for $\mathrm{Li}(\mathrm{Na})$-ion batteries.

In search [48] of 3D semiconducting carbon allotropes with proper bandgaps and promising optoelectronic properties, there was found a new structural 3D carbon modification (different from CHs) for the new emerging all- carbon optoelectronics with use of acetylenic linkages. It is a direct-gap semiconductor and possibly possesses the strongest optical transition coefficient.

Along with hydrogen storage or various other energyrelated applications porous 3D carbon materials [49] and in particular CHs seem to be highly prospective for molecular sieving in membranes made from such structures.

\section{Absorption of noble gases in carbon honeycombs}

First absorption experiments [1,5] were made with the heavier rare gases krypton and xenon (Fig. 5) to ensure the high levels of diffraction signals and consequently a high enough accuracy of the determined absorption levels. These studies were also performed applying the high-energy electron diffraction setup equipped with the helium cryostat of a specific configuration. In these first experiments, it had been found the procedure, which could ensure the high levels of absorption.

In the proposed method gaseous krypton and xenon were first deposited on the carbon substrate well below the sublimation temperatures typical for these gases in the specific vacuum conditions of this experiment, and good quality polycrystalline films were observed (Fig. 5). After warming such films up to temperatures a few degrees lower as compared with the sublimation points ( $42 \mathrm{~K}$ for $\mathrm{Kr}$ and $59 \mathrm{~K}$ for $\mathrm{Xe}$ ) and keeping at these temperatures several minutes peaks corresponding to a polycrystalline phase gradually disappeared. However distinct residual signals with respect to a pure carbon substrate remain. The intensity of a difference signal was at further warming reduced in a step-like way (such steps correspond to "kept” lines in Fig. 5), but such signals remained [5]. This effect was still observed several dozen degrees higher than the sublimation tempera-
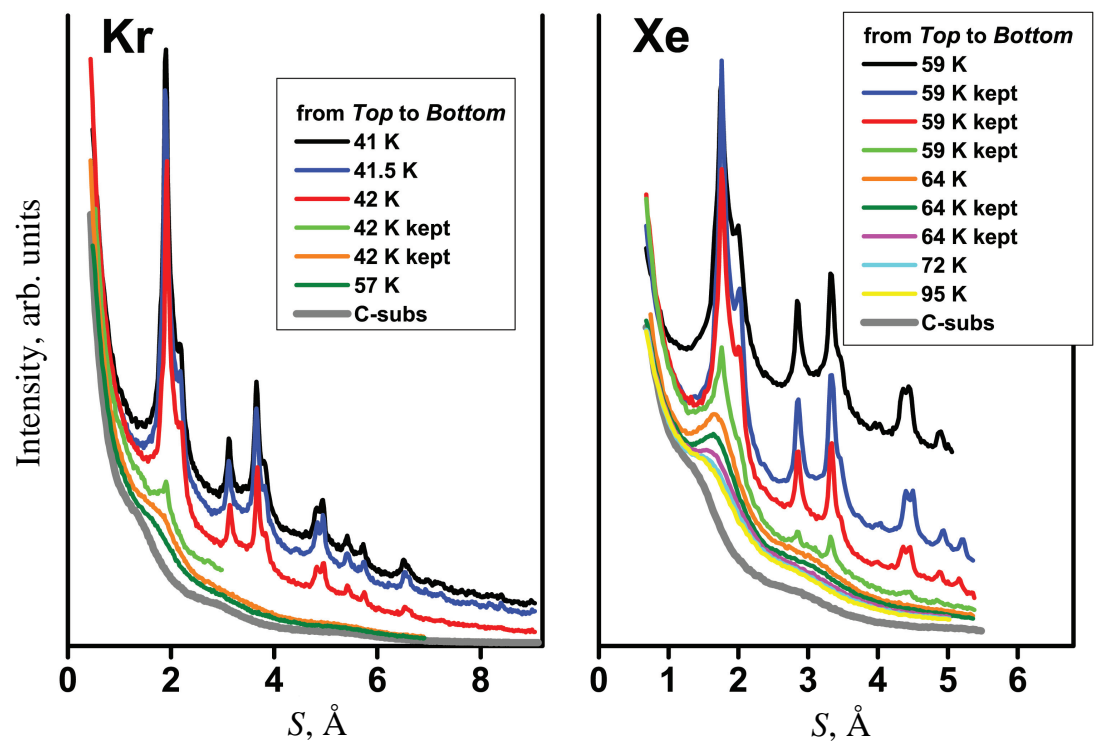

Fig. 5. (Color online) Evolution of the initial electron diffraction patterns for deposited $\mathrm{Kr}$ (a) and Xe (b) vs the scattering wave vector $S$ at warming. The diffraction curves for the carbon substrates (C-subs) are also shown [4,5]. 
tures characteristic of $\mathrm{Kr}$ and Xe due to very effective physical absorption of gases in a carbon matrix. And this owes to much stronger interaction of gas atoms with carbon walls as compared with interaction between gas atoms themselves.

Here we report also the high absorption capacity of carbon honeycomb relative to a lighter inert gas - argon. In these experiments the used procedure of $\mathrm{CH}$ film preparation was chosen in the way ensuring prevalence of typical random $\mathrm{CH}$ structures with average densities. The total picture in general is similar to observation of $\mathrm{Kr}$ and $\mathrm{Xe}$ absorption described above. First gaseous Ar was deposited at $\sim 15 \mathrm{~K}$ and then fast absorption occurred at $\sim 25 \mathrm{~K}$. Especial attention should be paid to the observation of the wide but well defined peak(s) ascribed to argon captured in carbon honeycomb matrices (Fig. 6). This peak is mainly close in its position to the most intensive reflection (111) from bulk fcc argon. But along with (111) — like peaks in

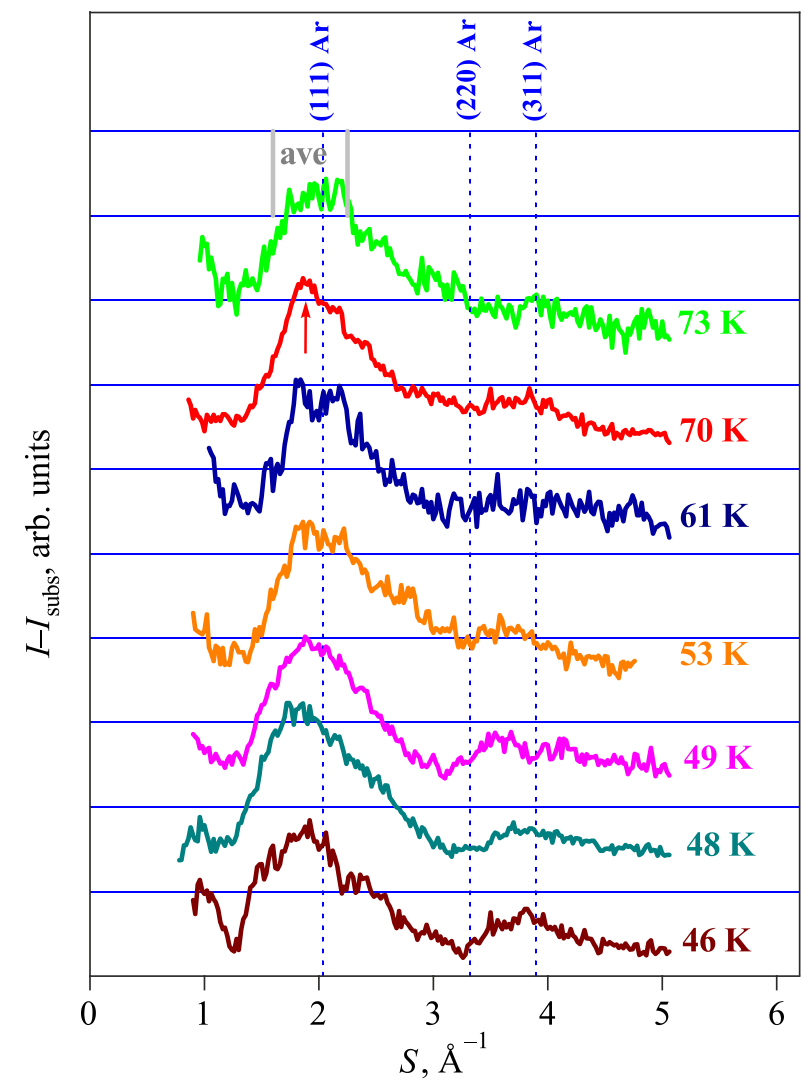

Fig. 6. (Color online) The excess $I-I_{\text {subs }}$ of experimental diffraction intensities from composites formed by argon deposited at $\sim 15 \mathrm{~K}$ and absorbed in carbon honeycomb matrices at $\sim 25 \mathrm{~K}$ relative to the intensities from a carbon substrate. The differences $I-I_{\text {subs }}$ are shown at elevated temperatures and shifted along vertical to make details visible. A wide but well defined peak is attributed to atoms with short range order captured in the carbon honeycomb matrices and is kept up to $\sim 80 \mathrm{~K}$ (maximal $T$ attained in this experiment) that is more than twice higher as compared with $T_{\text {subl }} \sim 32 \mathrm{~K}$ for Ar under typical vacuum conditions in this setup. diffractograms we can observe also a few lateral peaks which correspond in their positions to the hcp structure. This implies that argon atoms are not randomly distributed in channels of a carbon structure but form some kind of shortrange order in the probable mixture of fcc and hcp structures with the random stacking of the most dense basal planes.

Further the absorbate behavior at elevated temperatures was analyzed quantitatively (Fig. 7). It was found that complete desorption of argon atoms captured in carbon honeycomb does not occur even at temperatures more than twice higher as compared with the sublimation point ( $32 \mathrm{~K})$ of argon in its polycrystalline form in vacuum conditions of the experimental cell. This evidences in favor of physical absorption of argon with strong bonding in a carbon matrix. We can also see that the general decay in Fig. 7 tends to split into at least two stages or more that correlates with the previous observation [4,5] of the stepwise decrease of the absorbed $\mathrm{Kr}$ and $\mathrm{Xe}$ amounts in $\mathrm{CH}$ matrices. This effect is ascribed to the capture of argon atoms in channels with different sizes. Indeed it can be expected that in smaller channels bonding with walls will be stronger, and Ar atoms in such surrounding are firmly attached to walls up to very high temperatures. Over the whole interval a slight nearly "linear" contribution to intensities was noticed that can be ascribed to relaxation of structures formed in carbon channels towards to their better regularity.

Since the structure of carbon matrices were unknown in the first experiments on absorption of $\mathrm{Kr}$ and $\mathrm{Xe}$ [5] the analysis of the diffraction data from absorbates was based on the models of nearly spherical solid droplets. More realistic models (Fig. 8) were found and proposed later [4]. The simplified analysis with only one nanostructure for each of two considered there gases ( $\mathrm{Kr}$ and $\mathrm{Xe}$ ) (Fig. 8)

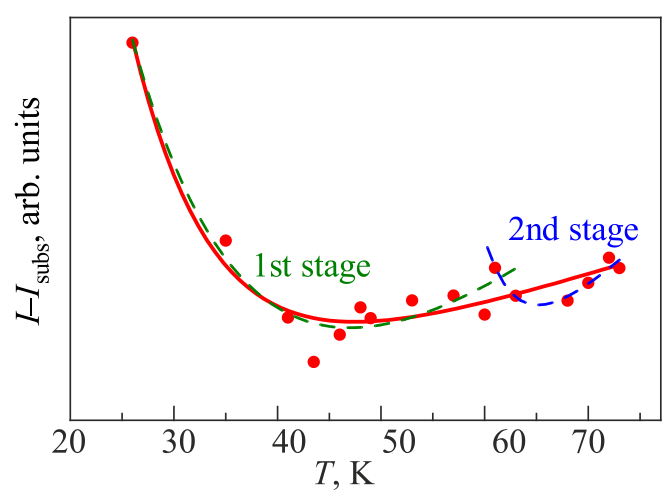

Fig. 7. (Color online) Temperature dependence of the diffraction intensity excess averaged over the 1st broad peak as shown in Fig. 6 relative to a signal from a carbon substrate. This access exhibits the exponential decay with $T$ and a noticeable two-stage character of Ar desorption in a wide temperature range up to $T$ values more than twice higher as compared with the sublimation point of polycrystalline argon in vacuum conditions of the used setup. 

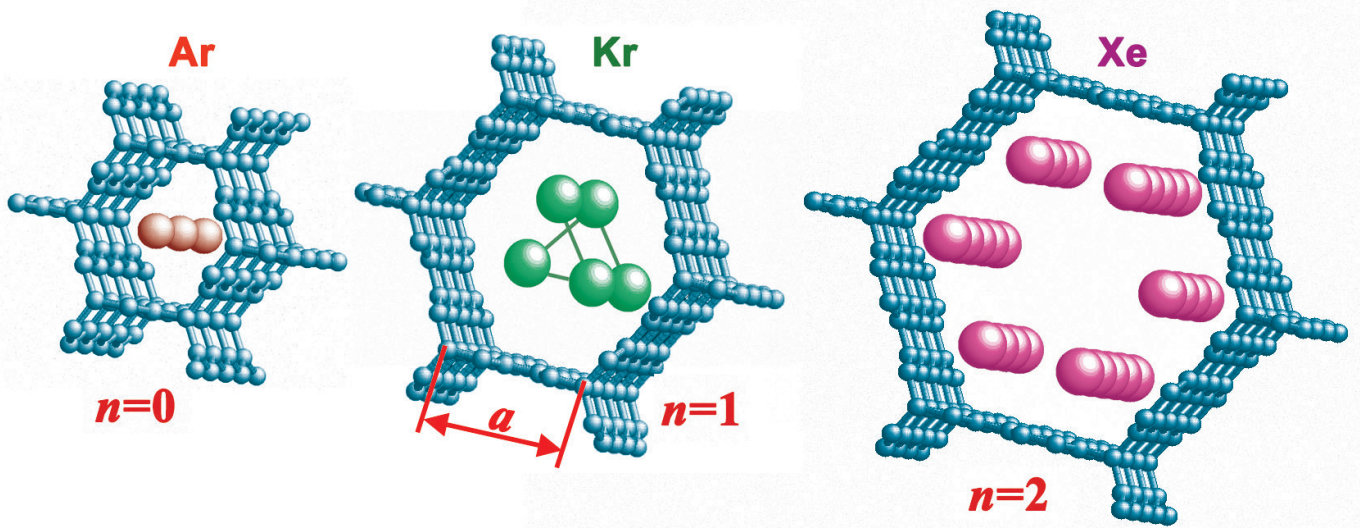

Fig. 8. (Color online) Most plausible arrangements of absorbed Ar, Kr and Xe atoms in the growing carbon honeycomb cells [4].

demonstrated that the experimental diffraction patterns from the honeycomb structures filled with absorbed gases correspond to the proposed models with the probabilities not worse than $\sim 45 \%$ for krypton in the carbon structure with $n=1$ and $27 \%$ for xenon in the matrix with $n=2$ (for carbon matrix description see Sec. 2). The better fit requires much larger model sets derived from theoretical model calculations, which take into account many opportunities for absorption as it was made for krypton in nanopores [50] or rare gases on single-wall carbon nanotubes [51].

\section{Capture of molecular gases in carbon honeycombs}

Since the processes of reversible sorption in $\mathrm{CHs}$ were studied by means of THEED this ensured the direct structure control in a wide temperature range down to liquid helium temperatures using the low-temperature cryostat. This method also allows evaluating the absorption levels for the gas storage in $\mathrm{CH}$ matrices as well as the upper-temperature limits for keeping absorbates in such structures. There were tested and applied two slightly different methods for gas absorbing. In our first experiments $[1,4,5]$ the high absorption ability of carbon films prepared by the method described in Sec. 2 and in more detail in [4] was attained if a gas (e.g. gaseous carbon dioxide) was first deposited on carbon substrates inside the cryostat well below the sublimation points of polycrystalline films $\left(T_{\text {subl }} \sim 86 \mathrm{~K}\right.$ for $\mathrm{CO}_{2}$ ). Good quality thin solid polycrystalline films with the specific and intrinsic molecular dynamics [52] formed right after deposition that was confirmed by the diffractograms typical of polycrystalline $\mathrm{CO}_{2}$. It has been shown previously applying the precise analysis of the experimental diffraction intensities [52] that in polycrystalline films molecular axes noticeably deviate from the cubic space diagonals of the $P a 3$ structure. The molecular tips tend to be oriented toward the empty spaces between two molecules in the nearest basal planes. When deposited films were gradually heated and kept slightly below the characteristic sublimation points, the sharp diffraction peaks corresponding to a polycrystalline state disappeared. But distinct residual signals remained and were still observed at temperatures far above the sublimation points.

In the later experiments with $\mathrm{CO}_{2}$ [6] the deposition temperature $\sim 80 \mathrm{~K}$ was close to the sublimation point and the absorption effect was very strong already during deposition (Fig. 9). When the gas was deposited on a carbon substrate we can see distinct peaks from polycrystalline $\mathrm{CO}_{2}$ films. But these polycrystalline peaks fast disappear already at $82 \mathrm{~K}$. The presence of absorbed gases is evident since we can see the wide but well-defined peaks in positions, which are close to the most intensive diffraction lines of polycrystalline $\mathrm{CO}_{2}$. But in our case gas molecules are captured in the $\mathrm{CH}$ matrices. It can be possible only if molecules are not randomly distributed in channels of a carbon matrix but form a short-range order. The specificity of composites formation is such that gaseous molecules were absorbed by the carbon supporting films due to fast diffusion and then were strongly bonded inside carbon matrices. This effect owes to stronger interaction with pore walls as compared with interaction between molecules themselves and can be characterized as physical absorption of gases with strong bonding in a carbon matrix.

The form and height of the broad absorbate peak change with temperature. This peak is apparently a superposition of two or more contributors. It becomes evident when such peaks split into at least two positions in some diffractograms. One of two peaks is close in position at $S$ $\sim 1.95 \AA^{-1}$ to the most intensive (111) diffraction line of polycrystalline $\mathrm{CO}_{2}$. This means that local molecule arrangements replicate the short-range order in crystalline carbon dioxide. But the other well-reproduced peak shown by arrow in Fig. 8(b) is located at smaller $S$, and mutual molecule positions and orientations corresponding to this peak require more detailed consideration. It can owe to the surface or interface broken symmetry in captured solidified gas fragments that may result in additional diffraction peaks, which are not typical of bulk crystals [53]. The important question is how atoms and molecules can be distributed inside porous carbon matrices. The exact answers 

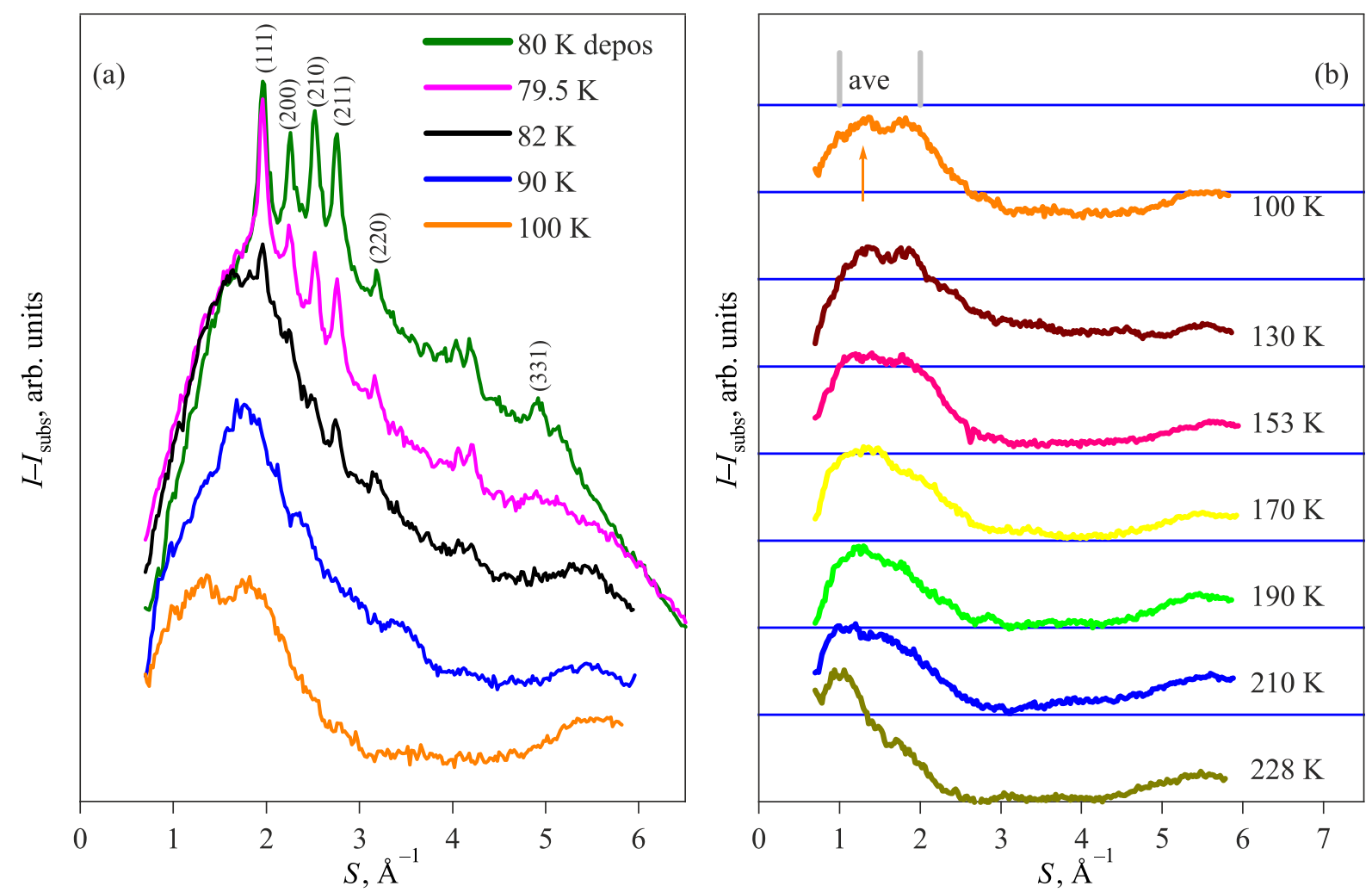

Fig. 9. (Color online) The excess $I-I_{\text {subs }}$ of experimental diffraction intensities from composites formed by carbon dioxide absorbed in carbon honeycomb matrices during deposition closely to $T_{\text {subl }}$ of $\mathrm{CO}_{2}$ in vacuum relative to the intensities from a carbon substrate (a). On the right (b) the differences $I-I_{\text {subs }}$ are shown at elevated temperatures and shifted along vertical to make details visible. A wide but well defined peak is attributed to molecules with short range order captured in the carbon honeycomb matrices and is still visible up to $\sim 230 \mathrm{~K}$ (maximal $T$ attained in this experiment) that is about three times higher as compared with $T_{\text {subl }} \sim 86 \mathrm{~K}_{\text {for }} \mathrm{CO}_{2}$ under typical vacuum conditions in the used setup [6].

can be obtained by direct modeling such composites applying (e.g.) the Monte Carlo method [54-56].

Further temperature evolution of absorbates was similar for both methods of gas absorbing. Considering a difference between experimental intensities $I$ from composites and $I_{\text {subs }}$ from a carbon substrate (Fig. 9) we can monitor the ongoing processes. The samples with $\mathrm{CO}_{2}$ absorbed in carbon honeycomb matrices under heating up to $\sim 230 \mathrm{~K} \mathrm{ex}-$ hibit a presence of a signal from $\mathrm{CO}_{2}$ even at temperatures almost three times higher as compared with $T_{\text {subl }} \sim 86 \mathrm{~K}$ for $\mathrm{CO}_{2}$ under typical vacuum conditions in the column of our diffraction setup.

The temperature behavior of composites was analyzed by means of averaging intensities over first peak as it is shown in Fig. 9(b). Such averaged value is presented in Fig. 10 as a function of temperature. A distinct decline of this signal at growing temperatures from its highest value at the deposition temperature to about three times weaker intensity at $T \sim 230 \mathrm{~K}$ is observed. At least two stages in the temperature dependence shown in Fig. 10 can be distinguished. One starts at the deposition temperature and stretches up to $\sim 140 \mathrm{~K}$ while the other exhibits one more decrease of a signal between 140 and $\sim 230 \mathrm{~K}$. For the described experiment in carbon film preparation the electric current was varied to choose the regime when denser films form. In this way it was expected that the stronger bonding of the absorbed gas with cell walls will be obtained and the upper temperature limit for gas keeping inside the carbon

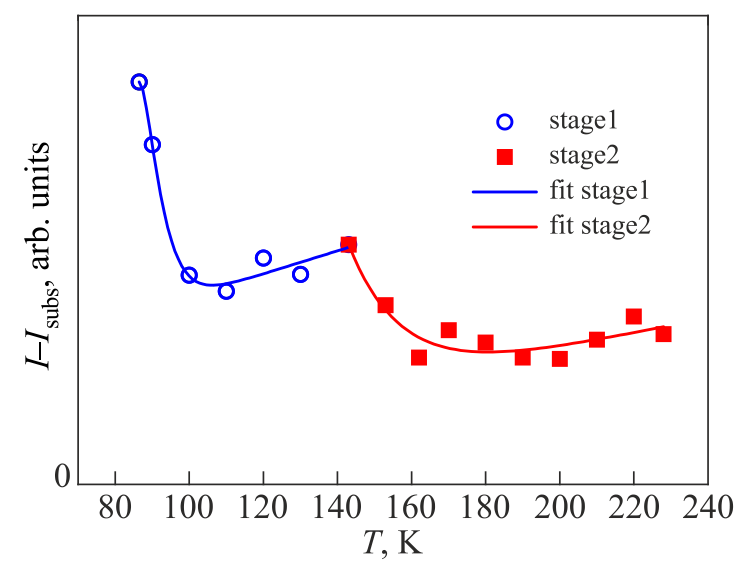

Fig. 10. (Color online) The diffraction intensity excess with respect to a signal from a carbon substrate as a function of temperature that exhibits two-stage character of $\mathrm{CO}_{2}$ desorption in the temperature range up to $T$ values almost three times higher as compared with the sublimation point of polycrystalline carbon dioxide in vacuum conditions of this experiment [6]. 
honeycomb matrices will be estimated. Therefore it is natural to suppose that inside cells $\mathrm{CO}_{2}$ molecules can interact with pore walls stronger or weaker depending on channel sizes. In the wide channels of random honeycomb structure, the $\mathrm{CO}_{2}$ molecules desorb at relatively low temperatures while in the denser structures hcA1 and hcZn0 owing to the stronger bonds with pore walls carbon dioxide can be preserved at much higher $T$ (see also Sec. 2). The experimental data were approximated using two different exponential decay functions for reduction of diffracted intensities ( $I-I_{\text {subs }}$ in Fig. 10) with temperature. We ascribe such a behavior to the molecule release from larger or thinner channels in the first and second stages respectively. A slight "linear" contribution to the intensities was detected that can be also ascribed to the relaxation of structures formed in carbon nanochannels towards their more regular arrangements in both stages.

Summing up we could conclude that complete desorption of carbon dioxide captured in the carbon honeycomb matrix does not occur even at the temperatures about three times higher as compared with the sublimation point of $\mathrm{CO}_{2}$ in a polycrystalline state in the typical vacuum conditions of experiment. And also it should be emphasized that the observed desorption as a temperature function has distinct two-stage character. This observation we ascribe to different bonds between $\mathrm{CO}_{2}$ molecules and walls inside CHs depending on channel configurations and sizes. Carbon dioxide molecules are kept by walls much stronger in the thinner channels of the densest honeycomb of an armchair type (hcA1) and in a densest structure of a zigzag type (hcZn0) as compared with weaker interactions with walls in random structures of a zigzag type.

Studies of carbon dioxide absorption targeted at least two areas of application aside from their direct scientific interest. First, we elucidate how effective such absorption is in order to capture this undesirable gas emitted in large amounts in industry and also when we use fossil fuels, and the second purpose is to find out if it is possible to store $\mathrm{CO}_{2}$ in carbon porous matrices for its recycling aiming further fuel production [57].

Absorption of the lighter molecular gases - nitrogen and carbon monoxide will be studied in the near future. But the most important absorbate for resolving the energy problem is hydrogen, the experiments with hydrogen storage in $\mathrm{CHs}$ are also planned.

Allowing for the absorption levels in the $\mathrm{CH}$ structures which depend on the cell sizes we can expect for hydrogen the relative densities of absorbate with respect to a matrix $\sim 8 \mathrm{wt} \%$ for $n=3$ (see Fig. 2 and Refs. 1, 4). High theoretical levels of physical absorption of $\mathrm{H}_{2}$ can also be attained (e.g.) in carbon foams based on the single-walled carbon nanotube bundles, where nanotubes are separated by external bridges between the tubes $[58,59]$. But by means of physical absorption, $\mathrm{He}$ and $\mathrm{H}_{2}$ may hardly be kept in a carbon matrix at high enough temperatures. It was reported about much stronger storage effect by means of hydrogenation of a matrix [60]. The ionization of carbon matrices as it is shown in the experiment for helium on a fullerene molecule [61] is one more option to increase the binding energy. Theoretically, the increased $\mathrm{H}_{2}$ storage capacity can be attained in the truncated carbon slit pores [62] or in open carbon frameworks [63], both are based on graphene. These and more methods for enhanced hydrogen storage are considered in the next section.

\section{Activated carbon with local graphene-like pore wall structures as potential enhanced hydrogen storage materials}

Carbon-based adsorbents belong to the most intensively studied and most attractive candidates for hydrogen storage, in particular for vehicular applications, because of their large availability, non-toxicity, low weight and low cost [64-77]. However, hydrogen physisorption on pure-carbon nanostructures does not fulfill the storage requirements fixed by US DOE [69-72] to target automobile applications. The main reason is the relatively low energy of adsorption of hydrogen in all-carbon structures (such as activated carbons, carbon nanotubes, or carbon nanohorns), in the range of about 4-9 kJ/mol [70-74,76,77]. The $a b$ initio calculations show that the binding energy of an $\mathrm{H}_{2}$ molecule on a flat graphene layer is of the order of 5.0-6.5 kJ/mol only, depending on the location of the adsorbed $\mathrm{H}_{2}$ with respect to graphene structure, with an equilibrium distance of 2.68-2.91 $\AA$ [72,79]. Apart from the energy factor, the sorbent topology is extremely important to assure an efficient but reversible storage [80,81]. Two parameters characterizing sorbent structure are usually monitored in adsorption studies: the surface area accessible for adsorption and the ratio of the pore volume with respect to the total volume of adsorbent. The geometrical shape of the pores influences both, surface and volume, parameters. Among pores of different shapes and forms, the micro-pores with pore width smaller than $2 \mathrm{~nm}$ are the most suitable for strong adsorption, as the adsorption energy increases when more than one wall interacts with adsorbed gas molecules.

The numerical modeling has been for a long time a preferred tool for evaluation of storage capacity of the hypothetical porous materials which have not been synthesized yet [82-84]. Moreover, as the adsorbing systems are naturally limited in the direction perpendicular to the pore surface, simulations can be carried out in boxes having relatively large lateral dimension. This option has been used. In particular, the calculations of hydrogen adsorption and storage in nanoporous, carbon-based sorbents [62,63,80, 81,85-88] have shown that: (i) low-temperature adsorption in pure porous carbons is very promising; (ii) graphene-like porous carbons can meet the DOE targets even at room temperature if the substrate-adsorbate interaction is strengthened by a modification of surface properties. Higher active adsorption surfaces are also necessary, although their quan- 
titative effect would depend on the surface topology. (iii) In modified materials (with increased $\mathrm{H}_{2}$-wall interaction, the nanopores of the width of 0.8-1.1 nm may stabilize 2-3 layers of hydrogen, and show high storage capacities. (iv) In fine, porous carbons with pore sizes between 0.8 and $1.1 \mathrm{~nm}$ and energies of adsorption equal to, or larger than $15 \mathrm{~kJ} / \mathrm{mol}$ could reach the DOE goals at room temperature. (v) An increase of the $\mathrm{H}_{2}$-wall interaction strength makes the adsorption-desorption delivery cycle very inefficient at low temperature but it improves delivery at room temperature. (vi) Similarly, in very small pores (with the width below $0.8 \mathrm{~nm}$ ) the adsorption-desorption cycle hardly reversible, as the total energy of adsorption in such pores is high, due to the cumulative effect of both confining pore walls.

It has been previously suggested that substitution of carbon in graphene-like pore wall by boron causes a local distortion of the perfectly planar graphene layer [89]. No such deviation from planarity has been observed in our $a b$ initio calculations. Hence, in this work, we modeled the substituted pore walls as flat sheets of graphene-like structures. The hydrogen molecules have been modeled by structureless superatoms interacting via the Lennard-Jones ( $\mathrm{LJ}$ ) potential. The interaction hydrogen-adsorbing surface was calculated assuming the additive LJ-type interaction of $\mathrm{H}_{2}$ super atom with all atoms of the pore wall within a cutoff distance of $15 \AA$. The parameters of the LJ potential were adjusted in such a way that the energy experienced by $\mathrm{H}_{2}$ over the surface agrees with the values determined by $a b$ initio calculations. This required modification not only of B- $\mathrm{H}_{2}$ interaction parameters but also of those of the nearest and next-nearest neighboring carbons. For $\mathrm{H}_{2}$ interactions with carbons more distant from boron usual values of $\mathrm{LJ}$ parameters have been used [90]. Feynman-Hibbs quantum corrections [91-93] were applied to all interactions.

Figure 11 shows a map of minimum energy for $\mathrm{H}_{2}$ adsorption over an infinite graphene surface with a single car- bon atom substituted by boron atom (at the $(0,0)$ position, left panel (a)). The map was calculated as follow: a probe $\mathrm{H}_{2}$ superatom was placed at $(x, y, z)$ point over the substrate and the minimum of interaction energy $z_{\min }(x, y)$ has been found by varying probe's $z$ coordinate: for each minimum value of $z_{\mathrm{min}}$, the $z$ coordinate of the minimum $\left(z_{\min }\right)$ has been also recorded. Two major conclusions come out from the analysis of $z_{\min }(x, y)$ energy landscape. First, the substitutional boron actually is not the location of the strongest energy of adsorption, but it contributes to a dramatic enhancement of the adsorption over the neighboring hexagons of the graphite lattice (in slightly off-center position). As the boron atom is larger than carbon, there is a local weak maximum of the energy at the boron, and it is located farther from the surface (Fig. 11(b)). Second, modification of the energy landscape extends far beyond the substitution site and is still perceptible at $7 \AA$ from it. It suggests that the adsorption properties of the partially substituted graphene surface may be strongly modified even if the substitution ratio is small.

To explore this possibility, we prepared the model slit pores built by graphene surfaces containing $1,2.5,5$, and $10 \%$ of boron. The localization of substituted sites was chosen at a random, but observing separation of at least three carbon atoms between them. This topological constraint allowed us to use the $a b$ initio results obtained for isolated substituted boron in an additive way. For low substitution ratio, the strong adsorption regions around the boron atoms remain well separated (Fig. 12(a)). However, already at substitution ratio of $5 \%$ these regions significantly overlap and the average adsorption energy increases concerning "pristine" graphite (from $E / k_{B}=600 \mathrm{~K}$ to $E / k_{B}=900 \mathrm{~K}$ ); the energy of the strongest adsorption site even doubles (Fig. 12(b)). At a substitution ratio of $10 \%$ the strongest adsorption energy reaches the value of $E / k_{B}=1400 \mathrm{~K}$.

The energy of adsorption is not the only parameter that should be optimized in efficient hydrogen sorbent. Another
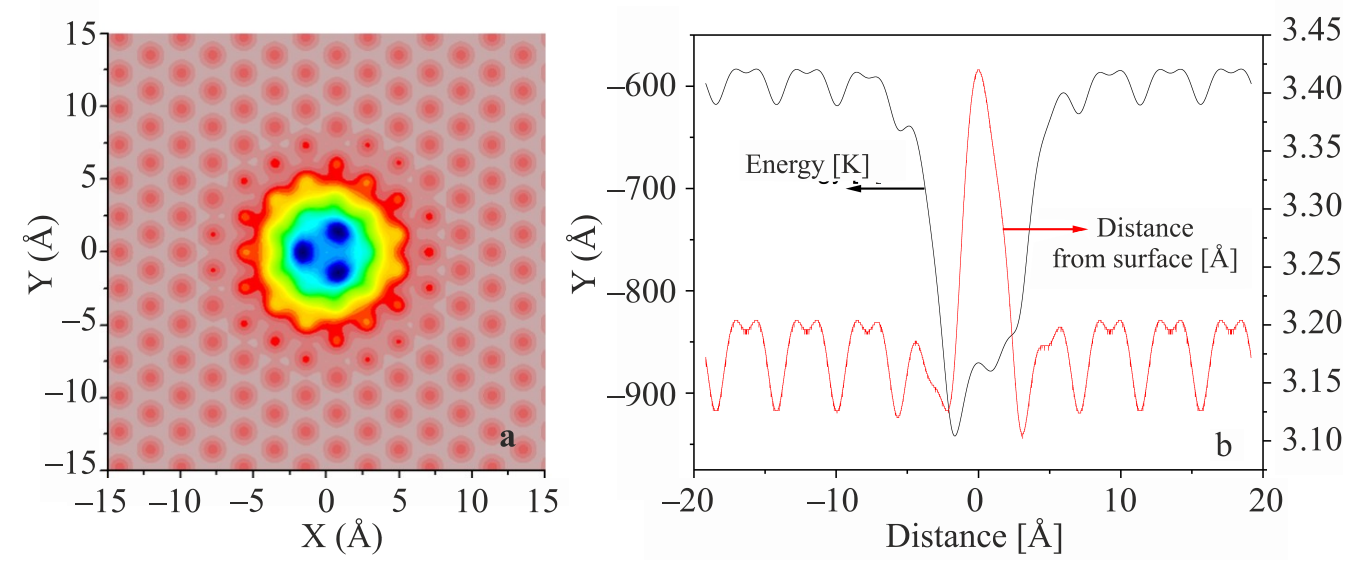

Fig. 11. (Color online) Energy landscape of $\mathrm{H}_{2}$ molecule on graphite with central carbon substituted by boron. Isoenergetic lines are separated by $E / k_{B}=10 \mathrm{~K}$ and go from $E / k_{B}=-580 \mathrm{~K}$ (pink gray) to $940 \mathrm{~K}$ (navy) (a). Energy of adsorption $E_{\text {min, }}$ and corresponding distance between $\mathrm{H}_{2}$ molecule and the substrate $Z_{\min }$, along the $(x, 0)$ line (b). 

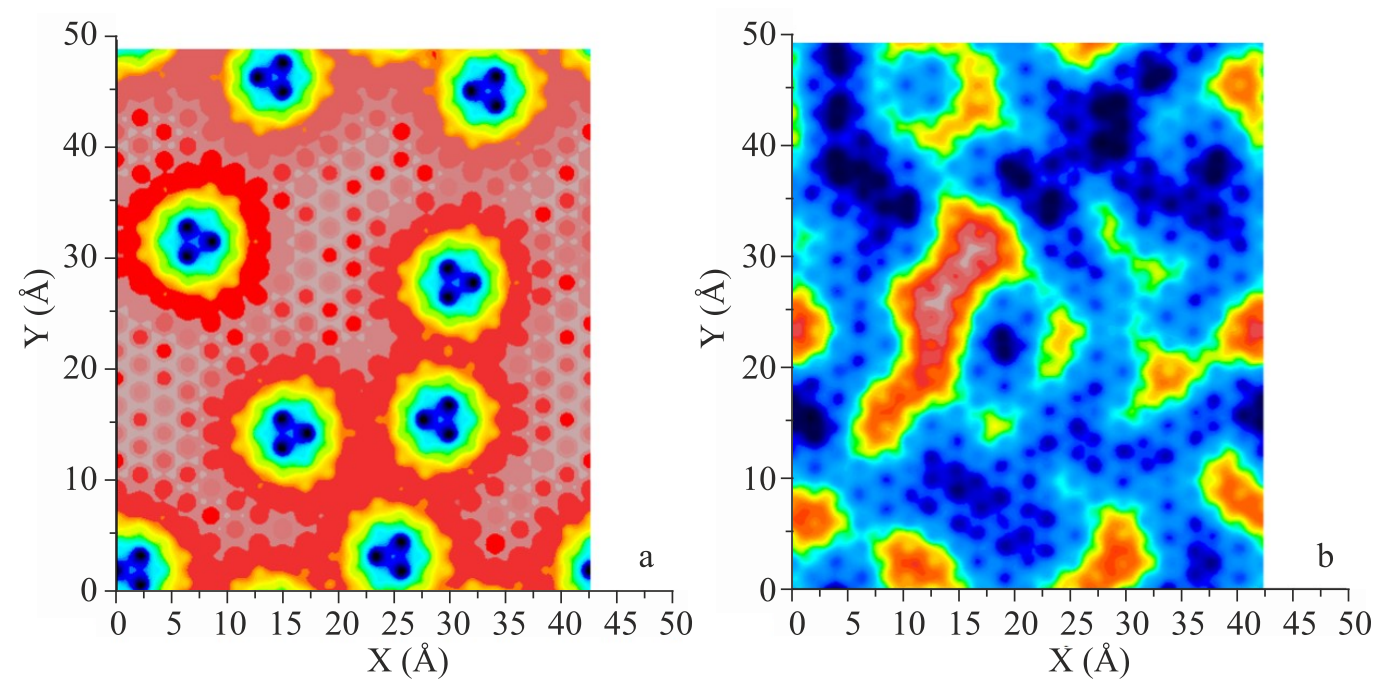

Fig. 12. (Color online) Energy landscape of $\mathrm{H}_{2}$ molecule on graphite surface containing 1\% (a) and 5\% (b) of substitutional boron atoms. Substitution is assumed to be random. Isoenergetic lines are separated by $E / k_{B}=10 \mathrm{~K}$; the color code on both graphs is identical in both panels: from $580 \mathrm{~K}$ (pink gray) to $1100 \mathrm{~K}$ (dark navy).

one is the total adsorption surface that should be maximized, in particular when the nanosize scaffold of the graphene is considered. This strategy has been already applied when preparing metal-organic frameworks (MOF) [94,95], covalent organic frameworks (COF) [96,97], and porous aromatic frameworks (PAF) [98]. Among carbon-based sorbents, PAFs should potentially show the highest adsorption capacity due to their high specific surface (more than $7000 \mathrm{~m}^{2} / \mathrm{g}$ ); unfortunately, their energy of adsorption is too low, i.e. on average lower than that of activated carbons.

In general, the structural heterogeneity introduced by different geometries causes a considerable decrease in the total amount of adsorbed gases (with respect to ideal slit graphene pores). Although there is no general proof of this statement, there are at least two physical reasons that lead to such behavior. First, in heterogeneous pores usually a non-negligible fraction of the pores' volume is difficult to access (e.a. pore's corners or interstitials sites in bundles of carbon nanotubes); in consequence, the effective specific surface area of the system is smaller. Second, the decrease of energy of hydrogen adsorption in heterogeneous structures usually leads to smaller uptake. In general, one cannot increase the adsorbed quantity by topological modification of the sorbent surface only. This conclusion is strongly supported by a recent computational study of hydrogen storage in covalently bonded graphenes [98]. This 3D structure is not able to adsorb at room temperature more than $4 \mathrm{wt} \%$ of hydrogen, even when the system properties are modified by dispersion of transition metals between the layers. An additional way of carbon nanostructures modification is necessary, a one that will allow simultaneous increase of both: adsorption surface and, if possible, also the adsorption energy.
One of the possibilities consists in preparation of nanoporous carbons using small polycyclic aromatic hydrocarbons as the building blocks [99-103]. It was estimated [100] that structures can have total surface area 2-3 times larger than the graphene. However, as we have shown in our paper [62] the increase of specific surface of the structure by pore wall fragmentation is usually accompanied by a substantial decrease of adsorption energy at the pore edges. Therefore we decide to test numerically what are the theoretical limits of adsorption in such systems. The goal will be to propose hypothetical structures that could potentially provide a guidance for future design and synthesis of carbons that strongly adsorb hydrogen.

The construction of sorbent using small fragments of graphene increases the surface accessible for adsorption, but modifies also the distribution of the adsorption energy inside the pore. The additional surface coming from the "edge" has lower energy than the infinite graphene layer [62]. The competition between increasing surface and decreasing average adsorption energy is the key feature defining the hydrogen uptake in different open geometries, including the MOF-, COF- or PAF-type structures. Therefore we have proposed three theoretical models of porous structures that could fulfill the requirements of efficient and reversible hydrogen sorbent. Although they are all hypothetic$\mathrm{cal}$, their synthesis is plausible. They are all constructed using polycyclic aromatic carbons as building units, bonded to form regular 3D structures. We used as the basic (building) molecules benzene, coronene (both resulting in very porous structures of specific surface above $6000 \mathrm{~m}^{2} / \mathrm{g}$ ), and a hypothetical supramolecule which consists of 43 hexagonal carbon rings (116 carbons). In the last case the specific surface of the resulting 3D porous structure is slightly lower, about $4600 \mathrm{~m}^{2} / \mathrm{g}$, but still much larger than the spe- 

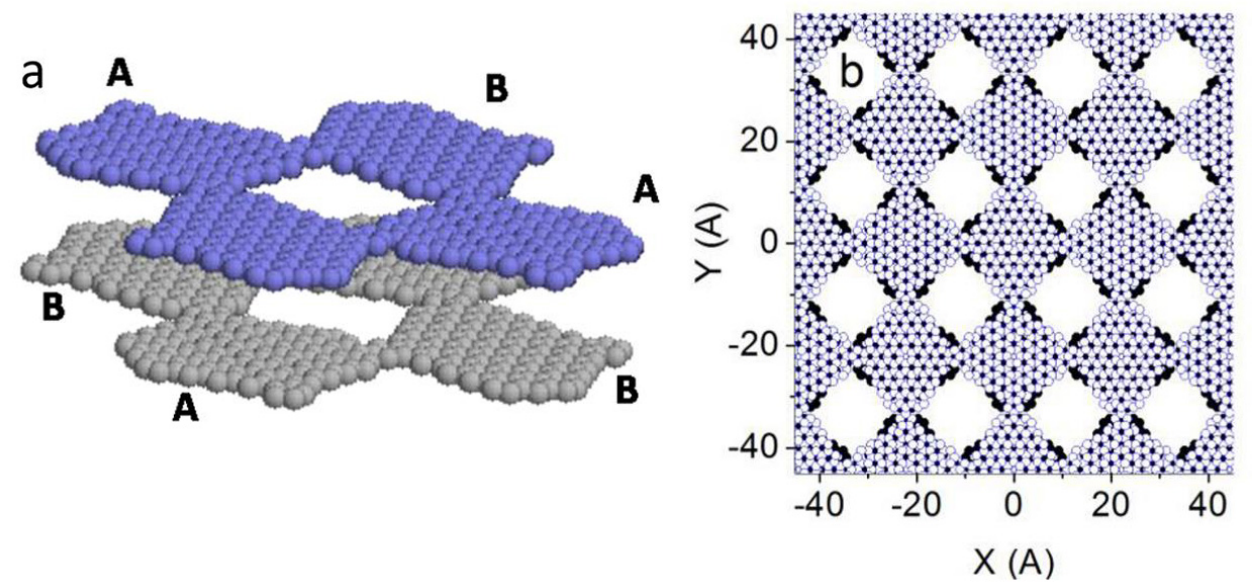

Fig. 13. (Color online) Hypothetical patch porous carbon structure. Basic pore unit consisting of eight supramolecules. The long axes of molecules A and B are orientated perpendicularly to each other (a). Infinite 3D patch structure that possesses slit pore geometry. The molecules in the subsequent walls in the $z$-direction follow ABAB... sequence. Two different colors have been used to assure contrast between two walls and have no physical meaning (b).

cific surface of an infinite graphene layer $\left(2600 \mathrm{~m}^{2} / \mathrm{g}\right)$. The large specific surfaces of benzene and coronene-based structures are mostly due to the contribution of molecules' edge to the total structure surface; the hypothetical supramolecule has only half of its surface coming from the edge contribution.

Using the hypothetical 43-rings supramolecule two 3D structures have been defined: a 3D patch structure (Fig. 13), and a 3D orthorhombic structure (Fig. 14). The first one has slit-type geometry, with the porous slit walls formed by bonded supramolecules. This structure is periodic, with the lattice constant $a=4.432 \mathrm{~nm}$ in a plane of the walls ( $x$ and $y$ directions; in the $z$ direction the lattice constant is defined by the slit pore width $d$, leading to the unit cell volume $V_{1}=a^{2} d$. The second structure has pseudocubic unit cell $\left(a=b=c=4.432 \mathrm{~nm}, V_{2}=a^{3}\right)$, which contains six supramolecules oriented perpendicularly to each other. In consequence, the 3D orthorhombic system has always lower mass density than the 3D patch structure (unless $d>2 a / 3$ ).

The presented and analyzed examples of hypothetical carbon structures for hydrogen storage emphasize that the optimal hydrogen adsorption cannot be achieved without a simultaneous optimization of both: adsorbent surface and its adsorption energy [104]. The attempts to increase the adsorption surface by fragmentation of pore walls leads always to the structural heterogeneity and introduces a dispersion of adsorption energies (a large number of low energy adsorption sites). Therefore, a simultaneous chemical modification of the surface that is able to modify adsorption energy landscape of the sorbent must be performed. In fine, the physical limits of hydrogen adsorption require preparing sorbents with average adsorption energy larger
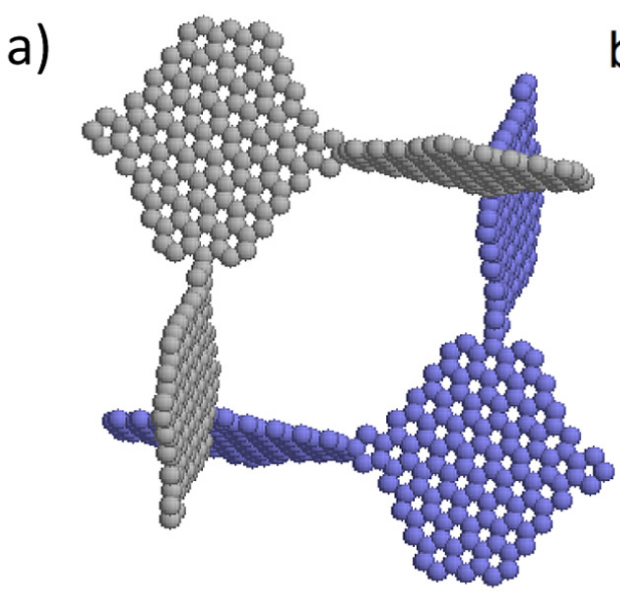

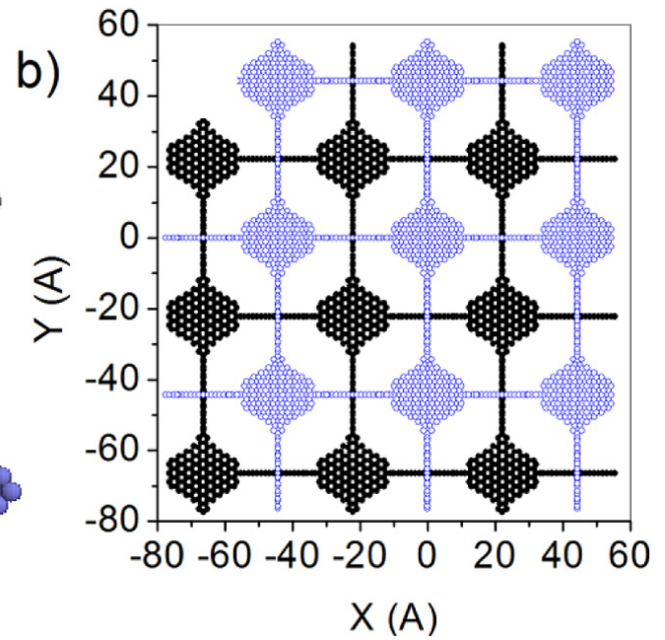

Fig. 14. (Color online) Hypothetical 3D orthorhombic porous carbon structure. Basic structure unit consisting of two bonded subunits (in gray and blue), shifted along the $z$ direction with respect to each other. Each subunit consists of three bonded supramolecules perpendicular to each other (in $x y, x z$, and $y z$ planes). The two subunits are bonded together (a). A periodic 3D orthorhombic structure. The period is equal to the distance between the centers of neighboring supramolecules having the same orientation (b). 
than $10 \mathrm{~kJ} / \mathrm{mol}$ (equally distributed over the whole surface) and, simultaneously, specific surfaces much higher than $3000 \mathrm{~m}^{2} / \mathrm{g}$ observed in the best existing carbons.

\section{Summary}

Cellular solids are a type of advanced materials with unique functionality. Widely distributed on Earth they have also numerous applications in industry, ecology, medicine and in everyday use.

The energy problem is presently very important and is expected to have only growing urgency in the nearest future. Carbon honeycomb $(\mathrm{CH})$ cellular structures considered in detail in this review offer unique potential for energy-related applications. Built from the carbon sheets known as graphene, $\mathrm{CHs}$ inherit some of graphene properties, while in contrast to graphene they display distinct 3D-architecture. With an ultra-large surface-to-volume ratio CHs promise important engineering applications. Most prominent is their ability to store large amounts of gases, making them good candidates for onboard storage of hydrogen - one of the cleanest, most perspective fuels of the future. $\mathrm{CH}$ matrices are offered also to be used as lightweight high capacity media for hydrogen storage in fuel cells. Besides chemically-doped, e.g., by nitrogen, $\mathrm{CH}$ structures can be efficient as metal-free cathodic electrocatalysts for oxygen reduction reactions in fuel cells replacing scarce platinum and precious alloys. They also can be effective as molecular sieves, i.e., can be used in developments of membranes with gas selection at the atomic level, etc. But the comprehensive understanding of the ways of their controlled and targeted production with corresponding variable properties is a key element for their further multipurpose utilizations. In particular, the presented and analyzed hypothetical carbon structures enhanced for hydrogen storage demonstrate that the optimal hydrogen adsorption cannot be achieved without a simultaneous optimization of both: adsorbent surface and its adsorption energy. This results in the conclusion that a simultaneous chemical modification of the surface in order to enhance the adsorption energy landscape of the sorbent must be performed.

3D porous carbon allotropes, in general, are also compelling candidates for the high-performance optoelectronics, with their diverse morphology opportune for targeted band gap engineering. Absorbing $\mathrm{Li}$ and $\mathrm{Na}$ they are also very attractive as anode material for lithium (sodium)-ion batteries.

Therefore we conclude that carbon-based 3D cellular structures offer a new material platform for alternative energy solutions and have a great potential for many applications not only for resolving such important energy-related problems as hydrogen storage but also further developments of photovoltaic technologies towards their overall wider usage. They also suggest new solutions for further development of microelectronic devices and sensor tech- nique, are predicted to be very promising for the production of high-performance Li-ion batteries and also molecular sieves for gas and liquid separations. The unique mechanical properties of $\mathrm{CHs}$ made them very perspective to be applied in many fields in particular at extreme mechanical conditions absorbing impact energy. They can also provide lightweight support, damp noises, can be used as scaffold for biological tissues, act as electrochemical porous electrodes, and the like.

1. N.V. Krainyukova and E.N. Zubarev, Phys. Rev. Lett. 116, 055501 (2016).

2. A.V. Dolbin, V.B. Esel'son, V.G. Gavrilko, V.G. Manzhelii, N.A. Vinnikov, I.I. Yaskovets, I.Yu. Uvarova, N.A. Tripachko, and B.A. Danilchenko, Fiz. Nizk. Temp. 39, 790 (2013) [Low Temp. Phys. 39, 610 (2013)].

3. A.V. Dolbin, V.B. Esel'son, V.G. Gavrilko, V.G. Manzhelii, N.A. Vinnikov, R.M. Basnukaeva, I.I. Yaskovets, I.Yu. Uvarova, and B.A. Danilchenko, Fiz. Nizk. Temp. 40, 317 (2014) [Low Temp. Phys. 40, 246 (2014)].

4. N.V. Krainyukova, J. Low Temp. Phys. 187, 90 (2017).

5. N.V. Krainyukova, Fiz. Nizk. Temp. 35, 385 (2009) [Low Temp. Phys. 35, 294 (2009)].

6. N.V. Krainyukova, Y.S. Bogdanov, and B. Kuchta, Fiz. Nizk. Temp. 45, 371 (2019) [Low Temp. Phys. 45, 325 (2019)].

7. Q. Yuan, H. Hu, J. Gao, F. Ding, Z. Liu, and B.I. Yakobson, J. Amer. Chem. Soc. 133, 16072 (2011).

8. T. Kawai, S. Okada, Y. Miyamoto, and A. Oshiyama, Phys. Rev. B 72, 035428 (2005).

9. Z. Zhang, A. Kutana, Y. Yang, N.V. Krainyukova, E.S. Penev, and B.I. Yakobson, Carbon 113, 26 (2017).

10. A. Kuc and G. Seifert, Phys. Rev. B 74, 214104 (2006).

11. A. Martínez-Mesa, L. Zhechkov, S.N. Yurchenko, T. Heine, G. Seifert, and J. Rubayo-Soneira, J. Phys. Chem. C 116, 19543 (2012).

12. Z. Zhu and D. Tománek, Phys. Rev. Lett. 109, 135501 (2012).

13. Z. Zhu, Z.G. Fthenakis, J. Guan, and D. Tománek, Phys. Rev. Lett. 112, 026803 (2014).

14. T. Maciel, Physics 9, 16 (2016).

15. B.E. Warren, X-Ray Diffraction, Addison-Wesley, Reading, MA (1969).

16. Y. Wei and R. Yang, Natl. Sci. Rev. (Oxford) 6, 324 (2019).

17. Z. Pang, X. Gu, Y. Wei, R. Yang, and M.S. Dresselhaus, Nano Lett. 17, 179 (2017).

18. Y. Gao, Y. Chen, C. Zhong, Z. Zhang, Y. Xiea, and S. Zhang, Nanoscale 8, 12863 (2016).

19. X. Gua, Z. Pang, Y. Wei, and R. Yang, Carbon 119, 278 (2017).

20. B. Morris, M. Becton, and X. Wang, Carbon 137, 196 (2018).

21. H. Wang, Q. Cao, Q. Peng, and S. Liu, Nanomater. 9, 109 (2019).

22. T. Tan, S.-Z. Chen, X.-H. Cao, W.-X. Zhou, F. Xie, and K.-Q. Chen, J. Appl. Phys. 122, 024304 (2017).

23. S.-Z. Chen, W.-X. Zhou, J.-F. Yu, and K.-Q. Chen, Carbon 129, 809 (2018). 
24. Y. Liu, J. Liu, S. Yue, J. Zhao, B. Ouyang, and Y. Jing, Phys. Status Solidi 255, 1700680 (2018).

25. L. Xie, H. An, C. He, Q. Qin, and Q. Peng, Nanomater. 9, 156 (2019).

26. J. Zhang and C. Wang, J. Phys. Chem. C 121, 8196 (2017).

27. F. Meng, C. Chen, D. Hu, and J. Song, J. Mech. Phys. Sol. 109, 241 (2017).

28. J. Zhang and Q. Xiong, Phys. Chem. Chem. Phys. 20, 4597 (2018).

29. W. Wang, C. He, L. Xie, and Q. Peng, Nanomater. 9, 487 (2019).

30. L. Yi, T. Chang, X.-Q. Feng, Y. Zhang, J. Wang, and B. Huang, Carbon 118, 348 (2017).

31. S.-Z. Chen, F. Xie, F. Ning, Y.-Y. Liu, W.-X. Zhou, J.-F. Yu, and K.-Q. Chen, Carbon 111, 867 (2017).

32. Y. Han, J.-Y. Yang, and M. Hu, Nanoscale 10, 5229 (2018).

33. Z. Wei, F. Yang, K. Bi, J. Yang, and Y. Chen, Carbon 113, 212 (2017).

34. X.-K. Chen, J. Liu, D. Du, Z.-X. Xie, and K.-Q. Chen, J. Phys.: Condens. Matter 30, 155702 (2018).

35. H. Zhang, S. Hu, H. Wang, Y. Chen, H. Wang, and Y. Ni, Chin. J. Phys. 59, 567 (2019).

36. J. Zhang, Carbon 137, 196 (2018).

37. N.T. Hung, A.R.T. Nugraha, and R. Saito, Carbon 125, 472 (2017).

38. Z. Pang, X. Gu, Y. Wei, and R. Yang, Mat. Today Phys. 5, 72 (2018).

39. S. Wang, D. Wu, B. Yang, E. Ruckenstein, and H. Chen, Nanoscale 10, 2748 (2018).

40. Z. Yang, G. Lan, B. Ouyang, L.-C. Xu, R. Liu, X. Liu, and J. Song, Mat. Chem. Phys. 183, 6 (2016).

41. Y. Chen, Y. Xie, Y. Gao, P.-Y. Chang, S. Zhang, and D. Vanderbilt, Phys. Rev. Mater. 2, 044205 (2018).

42. X. Liu and W. Guo, J. Appl. Phys. 123, 144301 (2018).

43. Y. Lu, Y. Ma, Y. Ma, T. Zhang, Y. Yang, L. Wei, and Y. Chen, J. Am. Chem. Soc. 140, 11538 (2018).

44. I.-Y. Jeon, H.-J. Choi, M. Choi, J.-M. Seo, S.-M. Jung, M.-J. Kim, S. Zhang, L. Zhang, Z. Xia, L. Dai, N. Park, and J.-B. Baek, Sci. Rep. 3, 1810 (2013).

45. J. Liu, X. Li, Q. Wang, Y. Kawazoe, and P. Jena, J. Mater. Chem. A 6, 13816 (2018).

46. L. Shi, A. Xu, and T. Zhao, J. Phys. Chem. C 122, 21262 (2018).

47. J. Hua and X. Zhang, Eur. Phys. J. B 91, 76 (2018).

48. C. Zhong, W. Zhang, G. Ding, and J. He, Carbon 154, 478 (2019).

49. H. Singh and R.S. Myong, Adv. Mat. Sci. Engin. 2018, 9565240 (2018).

50. B. Kuchta, P. Llewellyn, R. Denoyel, and L. Firlej, Fiz. Nizk. Temp. 29, 1152 (2003) [Low Temp. Phys. 29, 880 (2003)].

51. L. Firlej and B. Kuchta, Adsorption 14, 719 (2008).

52. N. Krainyukova and B. Kuchta, J. Low Temp. Phys. 187, 148 (2017).

53. N.V. Krainyukova, Fiz. Nizk. Temp. 15, 620 (1989) [Sov. J. Low Temp. Phys. 15, 349 (1989)].
54. R. Etters, E. Flenner, B. Kuchta, L. Firlej, and W. Przydrozny, J. Low Temp. Phys. 122, 121 (2001).

55. L. Firlej, B. Kuchta, R. Etters, W. Przydrozny, and E. Flenner, J. Low Temp. Phys. 122, 171 (2001).

56. R.D. Etters and B. Kuchta, Fiz. Nizk. Temp. 19, 526 (1993) [Low Temp. Phys. 19, 373 (1993)].

57. E. Billig, M. Decker, W. Benzinger, F. Ketelsen, P. Pfeifer, R. Peters, D. Stolten, and D. Thränae, J. $\mathrm{CO}_{2}$ Utiliz. 30, 130 (2019).

58. F. Ding, Yu Lin, P.O. Krasnov, and B.I. Yakobson, J. Chem. Phys. 127, 164703 (2007).

59. A.K. Singh, J. Lu, R.S. Aga, and B.I. Yakobson, J. Phys. Chem. C 115, 2476 (2011).

60. A. Nikitin, X. Li, Z. Zhang, H. Ogasawara, H. Dai, and A. Nilsson, Nano Lett. 8, 162 (2008).

61. C. Leidlmair, Ya. Wang, P. Bartl, H. Schöbel, S. Denifl, M. Probst, M. Alcamí, F. Martín, H. Zettergren, K. Hansen, O. Echt, and P. Scheier, Phys. Rev. Lett. 108, 076101 (2012).

62. L. Firlej, B. Kuchta, A. Lazarewicz, and P. Pfeifer, Carbon 53, 208 (2012).

63. B. Kuchta, L. Firlej, A. Mohammadhosseini, P. Boulet, M. Beckner, J. Romanos, and P. Pfeifer, J. Am. Chem. Soc. 134, 15130 (2012).

64. R. Strobel, J. Garche, P.T. Moseley, L. Jorissen, and G. Wolf, J. Power. Sour. 159, 781 (2006).

65. B. Panella, M. Hirscher, and S. Roth, Carbon 43, 2209 (2005).

66. L. Zubizarreta, E.I. Gomez, A. Arenillas, C.O. Ania, J.B. Parra, and J.J. Pis, Adsorption 14, 557 (2008).

67. H.-M. Cheng, Q.-H. Yang, and C. Liu, Carbon 39, 1447 (2001).

68. V. Meregalli and M. Parrinello, Appl. Phys. A 72, 143 (2001).

69. P. Benard and R. Chahine, Scripta Mater. 56, 803 (2007).

70. P. Benard and R. Chahine, Langmuir 17, 1950 (2001).

71. P. Benard and R. Chahine, Int. J. Hydr. Energy 26, 849 (2001).

72. S.K. Bhatia and A.L. Myers, Langmuir 22, 1688 (2006).

73. A. Gigras, S.K. Bhatia, A.V.A. Kumar, and A.L. Myers, Carbon 45, 1043 (2007).

74. G. Garberoglio, A.I. Skoulidas, and J.K. Johnson, J. Phys. Chem. B 109, 13094 (2005).

75. H. Chae, D.Y. Siberio-Perez, J. Kim, Y. Go, M. Eddaoudi, A. Matzger, M. O’Keeffe, and O.M. Yaghi, Nature 427, 523 (2004).

76. F. Rodriguez-Reinoso, Porous Carbons in Gas Separation and Storage, in: Combined and Hybrid Adsorbents, NATO Security Through Science Series, J.M. Loureiro and M.T. Kartel (eds.), Springer, Netherlands (2006), vol. 25, p. 133.

77. K.R. Matranga, A. Myers, and E.D. Glanst, Chem. Eng. Sci. 47, 1569 (1992).

78. J. Burress, M. Kraus, M. Beckner, R. Cepel, G. Suppes, C. Wexler, and P. Pfeifer, Nanotechnology 20, 204026 (2009).

79. D.Y. Sun, J.W. Liu, X.G. Gong, and Z.-F. Liu, Phys. Rev. B 75, 075424 (2007).

80. B. Kuchta, L. Firlej, P. Pfeifer, and C. Wexler, Carbon 48, 223 ( 2010 ).

81. L. Firlej, B. Kuchta, C. Wexler, and P. Pfeifer, Adsorption 15, 312 (2009). 
82. B. Kuchta, K. Rohleder, R.D. Etters, and J. Belak, J. Chem. Phys. 108, 3349 (1995).

83. D. Etters, B. Kuchta, and J. Belak, Phys. Rev. Lett. 70, 826 (1993).

84. B. Kuchta and T. Luty, J. Chem. Phys. 78, 1447 (1983).

85. L. Firlej, Sz. Roszak, B. Kuchta, P. Pfeifer, and C. Wexler, J. Chem. Phys. 131, 164702 (2009).

86. B. Kuchta, L. Firlej, R. Cepel, P. Pfeifer, and C. Wexler, Colloids Surfaces A 357, 61 (2010).

87. B. Kuchta, L. Firlej, Sz. Roszak, and P. Pfeifer, Adsorption 16, 413 (2010).

88. B. Kuchta, L. Firlej, A. Mohammadhosseini, M. Beckner, J. Romanos, and P. Pfeifer, J. Mol. Modeling 19, 4079 (2013).

89. Y.-H. Kim, Y. Zhao, A. Williamson, M.J. Heben, and S.B. Zhang, Phys. Rev. Lett. 96, 016102 (2006).

90. V. Buch, J. Chem. Phys. 100, 7610 (1994).

91. Q. Wang and J.K. Johnson, J. Phys. Chem. B 103, 277 (1999).

92. P. Kowalczyk, H. Tanaka, R. Hoyst, K. Kaneko, T. Ohmori, and J. Miyamoto, J. Phys. Chem. B 109, 17174 (2005).

93. V.A. Kumar, H. Jobic, and S.K. Bhatia, Adsorption 13, 501 (2007).

94. N.L. Rosi, J. Eckert, M. Eddaoudi, D.T. Vodak, J. Kim, M. O’Keeffe, and O.M. Yaghi, Science 300, 1127 (2003).

95. J. Sculley, D. Yuan, and H.-C. Zhou, Energy Environ. Sci. 4, 2721 (2011).

96. D. Cao, J. Lan, W. Wang, and B. Smit, Angew. Chem., Int. Ed. 48, 4730 (2009).

97. H. Furukawa and O.M. Yaghi, J. Am. Chem. Soc. 131, 8 (2009).

98. J. Lan, D. Cao, W. Wang, T. Ben, and G.J. Zhu, Phys. Chem. Lett. 1, 978 (2010).

99. H.K. Chae, D.Y. Siberio-Perez, J. Kim, Y. Go, M. Eddaoudi, A.J. Matzger, M. O’Keeffe, and O.M. Yaghi, Nature 427, 523 (2004)

100. N. Park, S. Hong, G. Kim, and S.-H. Jhi, J. Am. Chem. Soc. 129, 8999 (2007).

101. J. Gibson, M. Holohan, and H.L. Riley, J. Chem. Soc. 456, (1946).

102. H.L.Q. Riley, Rev. Chem. Soc. 1, 59 (1947).

103. K. Kaneko, C. Ishii, M. Ruike, and H. Kuwabara, Carbon 30, 1075 (1992).

104. L. Firlej, B. Kuchta, and P. Pfeifer, Adv. Mater. 25, 5971 (2013).

\section{Поглинання атомних та молекулярних речовин у вуглецевих коміркових структурах}

\section{H.B. Крайнюкова, B. Kuchta, L. Firlej, P. Pfeifer}

Представлено короткий огляд останніх розробок в області поглинання атомарних та молекулярних речовин у вуглецевих коміркових структурах. Такі поглинальні об’єкти чітко виділяються з великого сімейства вуглецевих пористих матеріалів завдяки прогнозованій та вже спостереженій в експериментах дуже високій здатності до поглинання та збереження всередині різних речовин, які у звичайних умовах поза пористими матрицями часто існують лише у газоподібній формі. Висока здатність до адсорбції досягається завдяки одиночним графеновим стінкам, які розділяють сусідні комірки по всій структурі та забезпечують тї малу вагу. Ці властивості коміркових структур роблять їх дуже перспективними для численних технологічних застосувань таких, як зберігання водню в паливних елементах та молекулярне просіювання у мембранах, які виготовлені з таких структур, а також для їх використання у мікроелектроніці, фотоелектроніці або виробництві літій-іонних батарей. Незалежно від цільових застосувань гази $є$ хорошими кандидатами для зондування та вивчення самих вуглецевих матриць.

Ключові слова: вуглецеві стільники; адсорбати у вуглецевих коміркових структурах, $a b$ initio розрахунки адсорбатних структур, дифракція високоенергетичних електронів.

\section{Поглощение атомных и молекулярных веществ в углеродных ячеистых структурах}

\section{Н.В. Крайнюкова, B. Kuchta, L. Firlej, P. Pfeifer}

Представлен краткий обзор последних разработок в области поглощения атомарных и молекулярных веществ в углеродных ячеистых структурах. Такие поглощающие объекты четко выделяются из большого семейства углеродных пористых материалов благодаря прогнозируемой и уже наблюдавшейся в экспериментах очень высокой способности к поглощению и сохранению внутри различных веществ, которые в обычных условиях вне пористых матриц часто существуют только в газообразной форме. Высокая способность к адсорбции достигается благодаря одиночным графеновым стенкам, разделяющим соседние ячейки по всей структуре, обеспечивая ее малый вес. Эти свойства сотовых структур делают их весьма перспективными для многочисленных технологических применений таких, как хранение водорода в топливных элементах и молекулярное просеивание в мембранах, изготовленных из таких структур, а также для использования в микроэлектронике, фотоэлектронике или производстве литий-ионных батарей. Независимо от целевого применения газы являются хорошими кандидатами для зондирования и изучения самих углеродных матриц.

Ключевые слова: углеродные соты, адсорбаты в углеродных ячеистых структурах, $a b$ initio расчет адсорбатных структур, дифракция высокоэнергетичных электронов. 